\title{
Correction to: Tsunami Modeling in the South American Subduction Zone Inferred from Seismic Coupling and Historical Seismicity

\author{
Miguel Medina, ${ }^{1}$ Sebastián Riquelme, ${ }^{2}$ Mauricio Fuentes, ${ }^{1}$ (i) and Jaime Campos ${ }^{1}$
}

Correction to: Pure Appl. Geophys.

https://doi.org/10.1007/s00024-021-02808-w

Figure 4 has its axis labels switched. The corrected version of the same figure is provided below.

The original article can be found online at https://doi.org/10.1007/ s00024-021-02808-w.

\footnotetext{
1 Seismic Risk Program, University of Chile, Santiago, Chile. E-mail: miguel.medina@dgf.uchile.cl; mauricio@dgf.uchile.cl; jaime@dgf.uchile.cl

2 National Seismological Center, University of Chile, Santiago, Chile. E-mail: sebastian@csn.uchile.cl
} 


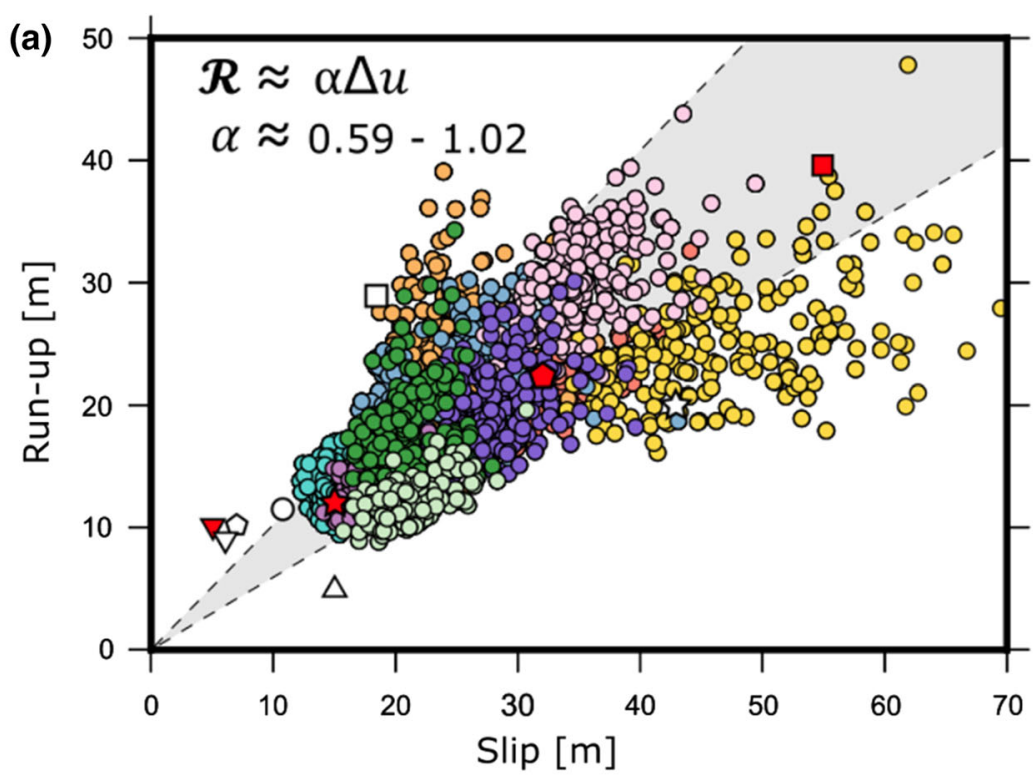

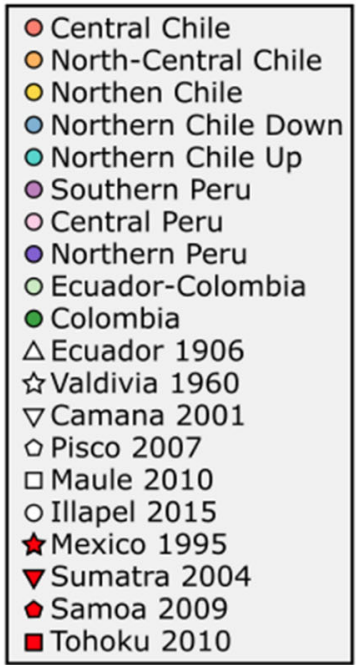

(b)

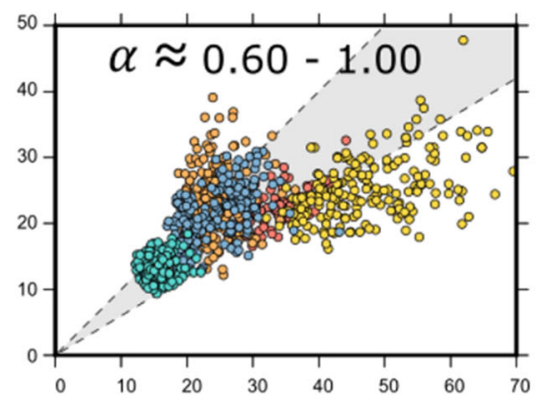

(c)

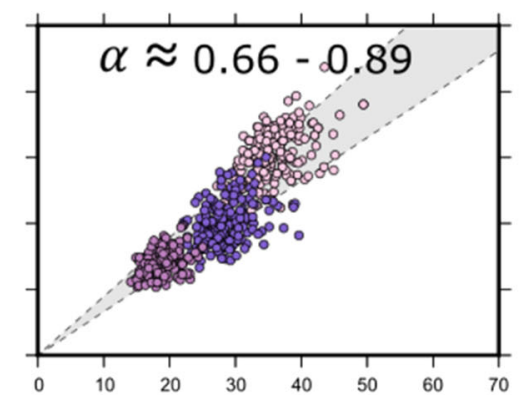

(d)

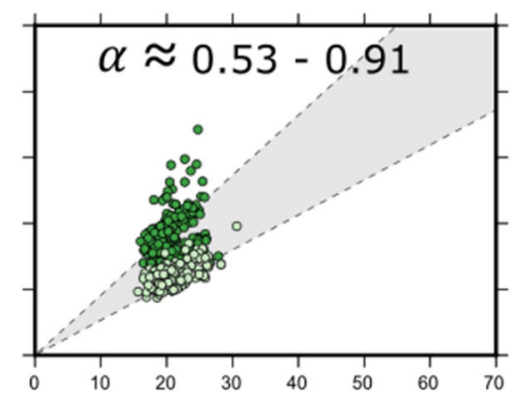

Figure 4

a Maximum run-up vs maximum slip for every modeled scenario in circles, fitted linear regression in dotted lines shows that run-up scales up to $59-102 \%$ of the slip for any given scenario. Significant historical subduction tsunamis in South America and the world are denoted by light and dark symbols, respectively. b Scenarios in Chile, $\mathbf{c}$ scenarios in Peru and $\mathbf{d}$ scenarios in Ecuador and Colombia

Publisher's Note Springer Nature remains neutral with regard to jurisdictional claims in published maps and institutional affiliations. 